\title{
Sentido de coherencia y consumo de sustancias en adolescentes españoles. ¿Depende el efecto del SOC de los patrones de consumo de sustancias del grupo de iguales?
}

\section{Sense of coherence and substance use in Spanish adolescents. Does the effect of SOC depend on patterns of substance use in their peer group?}

\author{
Irene García-Moya; Antonia JimÉneZ-Iglesias; \\ Carmen Moreno
} Department of Developmental and Educational Psychology.
University of Seville, Spain.
Enviar correspondencia a:

Irene García-Moya

Departmento de Psicología Evolutiva y de la Educación

Universidad de Sevilla

Calle Camilo José Cela, s/n

41018 Sevilla

irenegm@us.es

\section{Resumen}

Los objetivos de este trabajo fueron analizar las relaciones entre el sentido de coherencia (SOC) y el consumo de sustancias en los adolescentes españoles y el potencial efecto moderador de los patrones de consumo de sustancias en el grupo de iguales en dicha relación. La muestra constaba de 5475 adolescentes españoles de 15 a 18 años, participantes en la edición 2010 del estudio Health Behaviour in School-aged Children (HBSC). Los análisis estadísticos consistieron en análisis de cluster, para identificar grupos de adolescentes según los patrones de consumo de sustancias en su grupo de iguales, y regresión logística, con el SOC y los patrones de consumo en el grupo de iguales como predictores del consumo actual de tabaco y alcohol, episodios de embriaguez alguna vez en la vida y en la actualidad. Los resultados mostraron que un fuerte SOC parecía reducir la probabilidad de consumo de tabaco y episodios de embriaguez, pero no se asoció con el consumo actual de alcohol. Además, el efecto protector del SOC estaba moderado por los patrones de consumo del grupo de iguales. En concreto, el SOC tuvo un efecto protector significativo en los adolescentes cuyo grupo de iguales mostraba un patrón de no consumo o de frecuente consumo de alcohol y episodios de embriaguez ocasionales, pero el efecto del SOC desapareció si el patrón de consumo de los iguales incluia drogas ilegales. En conclusión, el SOC tiende a actuar como un factor protector individual respecto al consumo de sustancias durante la adolescencia, pero la influencia del grupo de iguales parece moderar dicho efecto protector del SOC.

Palabras clave: sentido de coherencia, adolescencia, patrones de consumo de sustancias en el grupo de iguales, consumo de tabaco, consumo de alcohol.

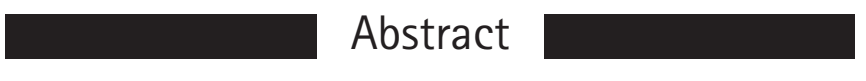

The aims of this work were to analyse the relationships between sense of coherence (SOC) and substance use among Spanish adolescents and to examine the potential moderator effect of the patterns of substance use in the peer group. Sample consisted of 5475 Spanish adolescents aged 15 to 18 from the 2010 edition of the Health Behaviour in School-aged Children (HBSC) study. Statistical analysis included cluster analysis to identify groups of adolescents according to their peer group's patterns of substance use and logistic regression with SOC and peers' pattern of consumption as predictors of current tobacco use, current alcohol use, life-time drunkenness and current drunkenness. The results showed that a strong SOC seemed to reduce the adolescents' likelihood of involving in tobacco use and drunkenness, but it was not associated with being a current drinker. In addition, the protective effect of SOC was moderated by peers' patterns of substance use. Specifically, SOC had a significant protective influence in adolescents whose peer group showed either a nonconsumption pattern or a pattern of frequent alcohol use and occasional drunkenness; but the protective effect of SOC disappeared if peers showed a pattern of consumption that included illegal drugs. In conclusion, SOC tends to act as a protective personal variable with respect to substance use during adolescence, but the influence exerted by the peer group seems to moderate the aforementioned protective effect of SOC.

Key Words: sense of coherence, adolescence, peers' patterns of substance use, tobacco use, alcohol use 
S ense of coherence (SOC) is the core concept in the salutogenic model proposed by Aaron Antonovsky (1987). It has been defined as a global orientation characterized by the capacity to perceive stimuli and life events as structured, understandable and predictable, the confidence in being able to mobilize the necessary resources for successful coping in the face of life demands, and the interpretation of those demands as challenges worthy of commitment and effort investment. In the face of life stressors, SOC seems to facilitate the selection and mobilization of the most appropriate resources (Amirkhan \& Greaves, 2003). For this reason, individuals with a strong SOC tend to show effective coping, even in adverse circumstances (Braun-Lewensohn, Sagy, \& Roth, 2011; Koposov, Ruchkin, \& Eisemann, 2003).

A notable body of evidence supports strong relationships of SOC with health and quality of life (Lindström \& Eriksson, 2010; Suominen, Blomberc, Helenius, \& Koskenvuo, 1999) and a remarkable increase in the research devoted to SOC has taken place in the last decades. Furthermore, SOC has sparked interest in experts from different disciplines: Medicine, Psychology, Sociology, to name a few.

Among the existing research on SOC, only a little proportion has been carried out in adolescent populations. However, and despite the original formulations by Antonovsky that described adolescent SOC as unstable and tentative, evidence to date clearly indicates that SOC tends to associate with positive health outcomes in adolescence (Cederblad \& Hansson, 1996; Eriksson \& Lindström, 2006). In addition, SOC is associated with the adoption of healthy lifestyles and lower risk of health-threatening behaviours (Wainwright et al., 2007). Specifically, a strong SOC has been related to regular physical activity (Sollerhed, Ejlertsson, \& Apitzsch, 2005) and appropriate dental hygiene (Ayo-Yusuf, Reddy, \& van den Borne, 2009), whereas a low SOC has been associated with unhealthy eating habits and substance use (i.e. Myrin \& Lagerström, 2006).

Substance use is one of the most frequently studied topics in the field of adolescent lifestyles. Research indicates that the onset of alcohol and tobacco use usually takes place in adolescence, being alcohol and tobacco the two most frequently used substances among Spanish adolescents (Delegación del Gobierno para el Plan Nacional sobre Drogas, 2009; Moreno et al., 2011). According to the data from a national survey on substance use among secondary students, the prevalence of alcohol and tobacco use (in the last 30 days) was 58.5\% and $32.4 \%$, respectively. Furthermore, drunkenness was a frequent phenomenon: $56.2 \%$ of adolescents aged 14 to $18 \mathrm{had}$ ever got drunk, and among individuals that had drunk alcoholic beverages in the last 30 days $49.6 \%$ had got drunk at least once in that period (Delegación del Gobierno para el Plan Nacional sobre Drogas, 2009).

Among the factors involved in the onset and escalation of substance use in adolescence, one of the most extensively studied aspects have been the influences from the peer group. In this developmental stage, when relationships with peers become more and more important and adolescents spend more time with their peer group (Brown, 2004; Rubin, Bukowski, \& Parker, 2006), the peers' behaviours become important deter- minants of substance use (De Vries, Engels, Kremers, Wetzels, \& Mudde, 2003; Morgan et al., 2012; Pettit, Bates, Dodge, \& Meece, 1999; Trujillo, Pérez, \& Scoppetta, 2011; Windle, 2000).

In fact, there is a high consensus about the idea that one of the most consistent and powerful predictors of substance use and other health-threatening behaviours in adolescence is being surrounded by close friends that are involved in those kinds of risk behaviours (Jaccard, Blanton, \& Dodge, 2005). This may be due to the fact that if peers are involved in substance use and show positive attitudes towards consumption, adolescents probably will get the impression that substance use is accepted in their social environment (Salamó Avellaneda, Gras Pérez, \& Font-Mayolas, 2010; Véronneau \& Dishion, 2010). Consequently, they will be more likely to show conformity with substance use (Kuntsche \& Stewart, 2009), since that kind of behaviour, to some extent, would serve to reinforce their attachment with their peer group (Guo, Hill, Hawkins, Catalano, \& Abbott, 2002; Moral Jiménez, Rodríguez Díaz, \& Sirvent Ruiz, 2005).

Nevertheless, the degree to which adolescents are open to the potential influences from the peer group is diverse and is modulated, among others, by individual factors (Cooper, Frone, Russel, \& Mudar, 1995; Trucco, Colder, Bowker, \& Wieczorek, 2011). Thus, certain personal variables can act as either protective or risk factors for substance use in adolescents.

Among risk factors, different motives for substance use have been described (Cooper et al., 1995; Windle, 1999). Substance use can be the result of inadequate coping strategies for negative emotions. Thus, certain individuals may see subtance use as an effective strategy to escape, avoid or regulate those negative emotions. Similarly, the search of positive emotional moods and new experiences seem to be related to substance use, and associations have been found between substance use in adolescence and sensation seeking, a personality trait that leads to the search of adventure and exciting experiences and is associated with several risk behaviours during adolescence, including substance use (Baker \& Yardley, 2002; Zimmermann, 2010; Zuckerman \& Kulhman, 2000). Deficits in self-control and low frustation tolerance have also been highlighted as individual risk factors (Contreras, Molina, \& Cano, 2012).

As for personal protective variables, some works have recently been published that reported significant associations between a strong SOC and a lower risk of substance use. Thus, Sagy, Shani, and Leibovich (2009) found less positive attitudes towards substance use in adolescents with a strong SOC. In addition, a strong SOC was significantly associated with lower consumption of tobacco (Glanz, Maskarinec, \& Carlin, 2003) and alcohol (Myrin \& Lagerström, 2006; Nilsson, Starrin, Simonsson, \& Leppert, 2007) in adolescence. Even more, among adolescents that reported having got drunk, those with a low SOC were more likely to experience alcohol-related problems compared to the ones with a high SOC (Nilsson et al., 2007).

Although the aforementioned works suggest that SOC can act as a protective mechanism against health-threatening behaviours such as substance use, analyses conducted to date have not included other important psychosocial factors 
in substance use during adolescence. In particular, despite the aforesaid importance attributed to the peer group as a predictor of substance use, to our knowledge, no studies have analysed the potential protective effect of SOC while taking into account the pattern of substance use in the adolescent's peer group.

For that reason the present study has two main aims: analysing the effect of SOC in adolescents' substance use (including tobacco use, alcohol use and drunkenness), and exploring the influence of SOC and patterns of substance use in the peer group simultaneously, so that not only the role of SOC in substance use will be analysed, but also information will be obtained about the possibility that the protective effect of SOC, if so, is moderated by the patterns of substance use in the adolescents' peer group. Therefore, this study is intended to answer the two following questions:

- Is SOC a protective factor that reduces the likelihood of adolescents' substance use? Drawing on the reviewed literature, SOC was expected to reduce the adolescent's likelihood to involve in substance use.

- Is the magnitude of the protective effect of SOC, if so, independent of the pattern of substance use in the peer group or is the SOC effect moderated by the peer group's pattern of substance use? Both factors have been proven to have a significant impact on adolescents' substance use, but evidence is scarce regarding the interaction between them. Therefore, a moderation effect was hypothesized, although its direction or magnitude remained to be explored.

\section{Method}

\section{Participants}

Sample consisted in 5475 Spanish adolescents aged 15 to $18(M=16.12, S D=1.08)$ selected for the 2010 edition of the WHO international survey Health Behaviour in Schoolaged Children (HBSC). A balanced percentage of boys and girls were part of the sample ( $49 \%$ boys and $51 \%$ girls). Adolescents aged 15 to 18 were selected because the prevalence of tobacco use, alcohol use and drunkenness has been found to experience a noticeable increase from 15 years onwards.

\section{Measures}

Variables in the present study have been assessed by means of specific items selected from the Health Behaviour in School-aged Children questionnaire in Spain. Some of them are specific instruments that have been developed outside the HBSC network but were included as part of the questionnaire, whereas others are questions specifically developed within the HBSC international survey. In addition, some of the questions are mandatory for all the participating countries, whe- reas others are optional or even selected at a national level. The questionnaire had been approved by the Research Ethical Committee of the University of Seville.

For the purpose of this study, the following measures were used:

- Sense of coherence (SOC). This variable was measured by using the SOC-29 Scale (Antonovsky, 1987). It consists of 29 items answered in a Likert scale of 7 values with two bipolar anchoring phrases (e.g. Until now your life has had...1-No clear goals or purpose at all, 7- Very clear goals and purpose). The scale provides a global score as well as separate scores for each dimension (comprehensibility, manageability and meaningfulness). Drawing on the recommendation by the scale's author (Antonovsky, 1993), the global SOC score was employed and a Cronbach alpha of .87 was obtained in this sample.

For the purpose of the study, comparisons were carried out between adolescents with a high SOC (PC 75 or higher) and the rest of the adolescents in the sample. The strategy of using cut-off points based on tertiles or quartiles has been frequently employed in the study of SOC due to the lack of validated cut-off points to distinguish among high, average and low levels of SOC (e.g. Koushede \& Holstein, 2009).

- Peers' patterns of substance use. This variable is based on the answers given to a series of items from the HBSC optional package related to the group of friends' behaviours (Most of the friends in my group...). Specifically, for the purpose of this study, items referred to tobacco use (...smoke cigarettes), alcohol use (... drink alcohol), drunkenness (...get drunk) and illegal drugs use (...have used drugs to get stoned) were considered. Answers to these questions were coded into ordinal variables with the following values:never or almost never, sometimes and very often. Those variables were entered in a cluster analysis and three different patterns of substance use in the peer group were obtained: a pattern of no consumption, a pattern of frequent alcohol use and occasional drunkenness and a pattern of frequent substance use including illegal drugs (for a detailed description of these three groups see Appendix 1 in the web).

- Tobacco and alcohol use. These variables are part of the mandatory questions in the assessment of tobacco and alcohol use from the HBSC international questionnaire and have been employed in the context of this survey to evaluate tendencies in tobacco and alcohol use since 1985. In addition, validation work of these items has been conducted within the HBSC international network that has supported their validity to evaluate these contents (i.e. Simons-Morton et al. 2009).

Specifically, four dependent variables were included in this study: current smoking, current alcohol use, lifetime drunkenness and current drunkenness involvement. The answers to the question How often do you smoke tobacco at present? were recoded to obtain 
the adolescents' current smoking status: Smoker (those who smoke every day, at least one a week, less than once $a$ week) versus non-smoker (the ones who answered I don't smoke). Similarly, the question At present, how often do you drink anything alcoholic? was used to evaluate current alcohol use regardless the kind of beverage (beer, wine, spirits of liquor and any other drink that contains alcohol). Answers were coded to obtain the adolescents' current drinking status: drinker versus non-drinker. Finally, two different aspects were included with respect to drunkenness. Lifetime drunkenness was assessed through the question Have you ever had so much alcohol that you were really drunk? where affirmative answers were coded as presence of this behaviour. In addition, current drunkenness involvement was analyzed by means of the question On how many occasions (if any) have you been drunk in the last 30 days?, which is an adaptation from the European School Survey Project on Alcohol and other Drugs (ESPAD) (Hibell et al., 2000). Again, affirmative answers were coded as presence of this behaviour.

\section{Procedure}

Information was obtained by means of anonymous on-line questionnaires that were filled in by the students during a regular school-hour in accordance with the HBSC international standardized procedure. The sessions were supervised by teaching staff and students' anonymity was ensured.

With regard to the statistical analysis procedure, separate logistic regression analyses were employed for every dependent variable: current smoking, current alcohol use, lifetime drunkenness and current drunkenness involvement. Predictors in those regression analyses were SOC and peers' pattern of substance use (defined by cluster of membership). In addition, an interaction term SOC x Peers' pattern of substance use was entered in the analysis to evaluate the possible moderator effect of peers' substance use in the associations between SOC and the examined subtance use behaviours.

\section{Results}

Results from separate logistic regression for current smoking, current alcohol use and drunkenness are presented in tables 1 to 4 .

As can be seen in table 1, peers' substance use significantly increased adolescent's likelihood of current smoking. Particularly, when compared to adolescents whose peer group provided a model of no consumption the ones with a peer group characterized by frequent alcohol use and occasional drunkenness $(0 R=3.98 ; 95 \%$ IC $=3.15-5.02)$ and, those with a peer group characterized by a frequent consumption of all types of substances including illegal drugs $(O R=9.43 ; 95 \%$ IC $=7.43$ - 11.96) were significantly more likely to be smokers. In con- trast, SOC reduced the likelihood of being a smoker $(\mathrm{OR}=.48$; $95 \%$ IC $=0.30-0.78)$. Also, a significant interaction effect was found $(p<.05)$. Particularly, the protective influence of SOC remained significant for adolescents whose friends showed frequent alcohol use and occasional drunkenness $(\mathrm{OR}=.64$; $95 \%$ IC $=.49-.84 ; p<.01)$. However, the S0C effect was negligible for the adolescents with the most negative peers' influence $(p=.72)$. As a whole, peers' substance use and SOC explained $19.6 \%$ of variability in adolescents' current tobacco use (Nagelkerke's $R^{2}=0.196$ ).

In the case of current alcohol use (see table 2), a global explanation of $18.6 \%$ was reached (Nagelkerke's $R^{2}=0.186$ ). An independent significant effect was found for peers' substance use. Again, peers' involvement in frequent alcohol consumption and occasional drunkenness (OR $=5.46$; $95 \%$ IC $=$ 4.45-6.70) or in high substance use including illegal drugs (OR $=7.38 ; 95 \% \mathrm{IC}=5.74-9.50)$ implied an increasing likelihood of current drinking alcohol $(p<.001)$. Both SOC and interaction effect were not significant ( $p=.11$ and $p=.05$, respectively).

Table 3 and 4 summarize data with respect to drunkenness.

SOC and peers' influence explained 26.9\% and 23.2\% of the variability in respectively ever get drunk and current drunkenness. Results indicate that adolescents were significantly more likely to have ever got drunk and have got drunk in the last 30 days if their peers provided a model of frequent alcohol consumption and occasional drunkenness or a model of high substance use including illegal drugs $(p<.001)$.

With respect to the influence of SOC, its effect was associated to a reduction in the likelihood of ever got drunk and having got drunk in the last 30 days, although the SOC effect depended on the kind of models of consumption provided by peers ( $p<.05$ and $p<.01$, respectively). Specifically, adolescents with a high SOC compared to the ones with a low SOC were significantly less likely to having ever got drunk if their peers showed a pattern of no consumption (OR $=0.62 ; 95 \%$ IC $=0.47-0.82 ; p<.01)$ or even if alcohol use and drunkenness were frequent in their peer group (OR $=0.70 ; 95 \%$ IC $=0.55$ $0.89 ; p<.01)$. However, the effect of SOC was not significant for adolescents whose peer group was involved in high substance use including illegal drugs $(p=0.35)$.

As for current drunkenness, the highest reduction of the likelihood of having got drunk in the last 30 days associated to high levels of SOC was found in adolescents with an absence of a model of consumption in their peer group $(O R=0.33$; $95 \%$ IC $=0.18-0.61 ; p<.01)$. Also, a more modest protective effect of a high SOC was found in the presence of a model of frequent alcohol use and occasional drunkenness in the peer group (OR $=.73 ; 95 \%$ IC $=0.57-0.94 ; p<.05)$. In the case of adolescents exposed to a model of high substance use including illegal drugs the effect of SOC became non significant ( $p$ $=.24)$. 
Table 1. Logistic regression of peers' patterns of substance use and SOC in current tobacco consumption

\begin{tabular}{|c|c|c|c|c|c|c|c|}
\hline & $B$ & E.T. & Wald & $d f$ & $p$ & $O R$ & $95 \%$ IC \\
\hline Peers'substance use & & & 348.638 & 2 & .001 & & \\
\hline (1)Frequent alcohol use and occasional drunkenness & 1.381 & .119 & 135.186 & 1 & .001 & 3.980 & {$[3.153,5.024]$} \\
\hline (2)Frequent substance use including illegal drugs & 2.244 & .121 & 342.157 & 1 & .001 & 9.430 & {$[7.434,11.961]$} \\
\hline SOC & -0.733 & .246 & 8.898 & 1 & .003 & 0.480 & {$[0.297,0.778]$} \\
\hline SOC $\times$ Peers'substance use & & & 6.309 & 2 & .043 & & \\
\hline SOC $\times$ Peers' substance use $(1)$ & 0.286 & .282 & 1.028 & 1 & .311 & 1.332 & {$[0.765,2.317]$} \\
\hline SOC x Peers' substance use(2) & 0.677 & .293 & 5.336 & 1 & .021 & 1.967 & {$[1.108,3.493]$} \\
\hline Constant & -2.250 & .102 & 485.601 & 1 & .001 & 0.105 & \\
\hline
\end{tabular}

Table 2. Logistic regression of peers' patterns of substance use and SOC in current alcohol consumption

\begin{tabular}{|c|c|c|c|c|c|c|c|}
\hline & $B$ & E.T. & Wald & $d f$ & $p$ & $O R$ & $95 \%$ IC \\
\hline Peers' substance use & & & 398.120 & 2 & .001 & & \\
\hline (1)Frequent alcohol use and occasional drunkenness & 1.698 & .104 & 264.188 & 1 & .001 & 5.461 & {$[4.450,6.702]$} \\
\hline (2)Frequent substance use including illegal drugs & 1.999 & .128 & 242.640 & 1 & .001 & 7.384 & {$[5.742,9.496]$} \\
\hline SOC & -0.179 & .113 & 2.491 & 1 & .114 & 0.836 & {$[0.669,1.044]$} \\
\hline SOC $\times$ Peers' substance use & & & 5.982 & 2 & .050 & & \\
\hline SOC $\times$ Peers' substance use $(1)$ & -0.460 & .190 & 5.875 & 1 & .015 & 0.631 & {$[0.435,0.916]$} \\
\hline SOC $x$ Peers' substance use(2) & -0.077 & .278 & 0.076 & 1 & .783 & 0.926 & {$[0.538,1.596]$} \\
\hline Constant & 0.289 & .061 & 22.821 & 1 & .001 & 1.335 & \\
\hline
\end{tabular}

Table 3. Logistic regression of peers' patterns of substance use and SOC in ever get drunk

\begin{tabular}{|c|c|c|c|c|c|c|c|}
\hline & $B$ & E.T. & Wald & $d f$ & $p$ & $O R$ & $95 \%$ IC \\
\hline Peers' substance use & & & 583.323 & 2 & .001 & & \\
\hline (1)Frequent alcohol use and occasional drunkenness & 1.825 & .091 & 405.443 & 1 & .001 & 6.201 & {$[5.192,7.406]$} \\
\hline (2)Frequent substance use including illegal drugs & 2.223 & .103 & 463.541 & 1 & .001 & 9.234 & {$[7.543,11.306]$} \\
\hline SOC & -0.473 & .141 & 11.231 & 1 & .001 & 0.623 & {$[0.473,0.822]$} \\
\hline SOC $\times$ Peers' substance use & & & 7.695 & 2 & .021 & & \\
\hline SOC $\times$ Peers' substance use $(1)$ & 0.120 & .186 & 0.414 & 1 & .520 & 1.127 & {$[0.783,1.622]$} \\
\hline SOC $x$ Peers' substance use(2) & 0.656 & .243 & 7.317 & 1 & .007 & 1.928 & {$[1.198,3.101]$} \\
\hline Constant & -1.020 & .068 & 225.520 & 1 & .001 & 0.361 & \\
\hline
\end{tabular}

Table 4. Logistic regression of peers' patterns of substance use and SOC in current drunkenness

\begin{tabular}{|c|c|c|c|c|c|c|c|}
\hline & $B$ & E.T. & Wald & $d f$ & $p$ & $O R$ & $95 \%$ IC \\
\hline Peers' substance use & & & 358.297 & 2 & .001 & & \\
\hline (1)Frequent alcohol use and occasional drunkenness & 1.840 & .125 & 215.331 & 1 & .001 & 6.297 & {$[4.925,8.051]$} \\
\hline (2)Frequent substance use including illegal drugs & 2.444 & .129 & 358.151 & 1 & .001 & 11.514 & {$[8.939,14.829]$} \\
\hline SOC & -1.113 & .313 & 12.628 & 1 & .001 & 0.329 & {$[0.178,0.607]$} \\
\hline SOC $\times$ Peers' substance use & & & 15.124 & 2 & .001 & & \\
\hline SOC $\times$ Peers' substance use $(1)$ & 0.803 & .338 & 5.644 & 1 & .018 & 2.232 & {$[1.151,4.329]$} \\
\hline SOC $x$ Peers' substance use(2) & 1.300 & .351 & 13.683 & 1 & .001 & 3.669 & {$[1.842,7.305]$} \\
\hline Constant & -2.452 & .111 & 487.209 & 1 & .001 & 0.086 & \\
\hline
\end{tabular}




\section{Discussion}

This work deals with two objectives. The first one is analysing the relationship between $\mathrm{SOC}$ and substance use during adolescence. As a second objective, we explore the potential moderation effect of the pattern of substance use in the peer group in the relationship between SOC and the adolescent's substance use.

SOC, which is the focus of this study, showed a protective effect with respect to substance use in adolescents, as hypothesized. Specifically, a high SOC was associated with lower risk of current tobacco use and in-life and current drunkenness. The former associations have been found in previous research, that illustrates that a strong SOC is associated with lower substance use (Glanz et al., 2003; Myrin \& Lagerström, 2006; Nilsson et al., 2007) and non-favourable attitudes towards consumption (Sagy et al., 2009). In fact, SOC favours the adoption of healthy behaviours and reduces health-threatening behaviours (Wainwright et al., 2007), such as substance use. All these findings are in line with the conceptualization of SOC as an asset that can improve the adolescents' ability to take sound health decisions. High SOC levels are the result of the capacity to understand and find meaning in the daily life activities and the disposal of resources to deal with stressful situations. Equally, SOC has been related with the use of more effective coping strategies (Amirkhan \& Greaves, 2003). Some of these mechanisms may have contributed to adolescents with a high SOC being less likely to get involved in the aforementioned health-threating substance use behaviours.

However, current drinking status didn't seem to be associated with the adolescents' SOC. This unexpected finding may be due to the fact that alcohol is the widest used substance among adolescents (Delegación del Gobierno para el Plan Nacional sobre Drogas, 2009), as well as the most widely accepted, given that alcohol use is not usually considered a problem if it is moderate and related to social leisure time (March Cerdá et al., 2010). Consistently with the idea that risk judgements are significantly related with the involvement on a given health-threatening behaviour (Essau, 2004), our data indicate that, despite not being related with current alcohol use, SOC is associated with a decreased likelihood of getting drunk, which may have to do with drunkenness being perceived as a problem behaviour by adolescents with a strong SOC which, in turn, leads them to mobilize towards healthier options. Furthermore, given that in the assessment of alcohol use differences are examined in terms of current drinking status (being a current drinker vs a current non-drinker), the possibility exists that significant differences associated to SOC levels appeared in the frequency or quantity of alcohol intake.

In addition, this work made it possible to analyse the role of SOC and peers' substance use simultaneously, which is important given that substance use in the peer group increased the adolescent's likelihood of involving in substance use themselves, as found in previous research (e.g. De Vries et al., 2003; Windle, 2000). Specifically, the protective effect of SOC on substance use showed a different magnitude depending on the pattern of substance use in the adolescents' peer group: the highest effect of SOC was observed in the case of non-user peers, and a lower but significant effect of SOC was found in adolescents whose peer group was involved in frequent alcohol use and occasional drunkenness. In contrast, when the adolescents' peer group showed frequent consumption including illegal drugs, the protective effect of SOC tended to disappear.

Although more research is needed in order to confirm and fully understand this finding, some hypotheses can be proposed. These results can probably be understood in light of the different meanings that the described patterns of substance use in the peer group may have. Thus, in the peer group of frequent alcohol use and occasional drunkenness, consumption seems to be experimental and can be related to social leisure time mainly at weekends (Delegación del Gobierno para el Plan Nacional sobre Drogas, 2009). In contrast, the use of illegal drugs have different implications since it is usually associated with a higher and more problematic use of other substances, both in this work and in previous research (Duncan, Duncan, \& Hops, 1998; Simões et al., in press). Therefore, adolescents whose peer group shows frequent substance use including illegal drugs may be more likely to perceive substance use as a predominant and an acceptable behaviour in their group (Salamó Avellaneda et al., 2010; Véronneau \& Dishion, 2010). Even more, according to the work by Schofffild, Pattison, Hill, and Borland (2001), adolescents may internalize those behaviours as part of the group norms that contribute to the definition of the group identity and, as a result, be more prone to show conformity with them (Kuntsche \& Stewart, 2009).

The present study has some limitations that should be taken into account. Firstly, the cross-sectional design does not allow drawing conclusions about causality. Also, the information source is the adolescent, which may imply some bias both with respect to their peers' behaviour (since adolescents may overestimate similarity with their friends) and their own behaviour. However, adolescents' reports have been considered reliable and accurate especially in surveys in which the anonymity and confidentiality of participants are warranted (Campanelli, Dielman, \& Shope, 1987), which is the case of the present study. Finally, the measures employed in the assessment of the adolescents' substance use in this study do not provide a complete view of the reality of substance use in the adolescents' life and, as a consequence, more in-depth assessment of this content as well as the incorporation of other key aspects related to substance use (e. g. perceptions of risks, group norms, emotional factors...) would undoubtedly contribute to a better understanding of the role of SOC in substance use and its interaction with the peer group's pattern of consumption.

Despite that, the present work has the strength of being one of the first studies devoted to the relationships between SOC and tobacco and alcohol use in adolescence and, to our knowledge, the first one in incorporating the role of the peer group in this analysis. In addition, this study contributes to deepening knowledge on the protective effect of SOC on substance use providing interesting and innovative research findings that besides have been obtained in a large sample, which makes it possible the generalization of these results (Hair, Anderson, Tatham, \& Black, 2008).

Furthermore, given that the present study means a first step in the analysis of the protective effect of SOC on subs- 
tance use during adolescence while taking into account the moderator effect of consumption in the peer group, this study underlines the importance of including social factors in the study of the relationships between SOC and risk behaviours and, in the case of substance use, it breaks ground to future research that includes other aspects of the relationships with peers, a wider variety of substances (incorporating other illegal drugs such as cannabis) and other meaningful contexts in the adolescents' lives, such as family, school or neighbourhood.

\section{Acknowledgements}

This research has been funded by an agreement signed between the Ministerio de Sanidad, Política Social e Igualdad, and the University of Seville (Spain). In addition, this work is supported by the Ministerio de Educacion through the National Program FPU [grant number: AP2009-0978].

\section{Conflict of interests}

The authors declare that they do not have any conflict of interests.

\section{References}

Amirkhan, J. H., \& Greaves, H. (2003). Sense of coherence and stress: The mechanics of a healthy disposition. Psychology \& Health, 18, 31-62. doi: 10.1080/0887044021000044233

Antonovsky, A. (1987). Unraveling the mystery of health. How people manage stress and stay well. San Francisco, USA: Jossey-Bass.

Antonovsky, A. (1993). The structure and properties of the sense of coherence scale. Social Science \& Medicine, 36, 725-733. http:// dx.doi.org/10.1016/0277-9536(93)90033-Z

Ayo-Yusuf, O. A., Reddy, P. S., \& Van den Borne, B. W. (2009). Longitudinal association of adolescents' sense of coherence with tooth-brushing using an integrated behaviour change model. Community Dentistry and Oral Epidemiology, 37, 68-77. doi: 10.1111/j.1600-0528.2008.00444.x

Baker, J. R., \& Yardley, J. K. (2002). Moderating effect of gender on the relationship between sensation seeking-impulsivity and substance use in adolescents. Journal of Child and Adolescent Substance Abuse, 12, 27-43. doi: 10.1300/J029v12n01_02

Braun-Lewensohn, O., Sagy, S., \& Roth, G. (2011). Coping strategies as mediators of the relationship between sense of coherence and stress reactions: Israeli adolescents under missile attacks. Anxiety, Stress \& Coping, 24, 327-341. doi: 10.1080/10615806.2010.494329

Brown, B. B. (2004). Adolescents' relationships with peers. In R. M. Lerner, \& L. Steinberg (Eds.), Handbook of adolescent psychology (2nd ed., pp. 363-394). New Jersey, USA: John Wiley \& Sons.
Campanelli, P. C., Dielman, T. E., \& Shope, J. T. (1987). Validity of adolescents' self reports of alcohol use and misuse using a bogus pipeline procedure. Adolescence, 22(85), 722.

Cederblad, M., \& Hansson, K. (1996). Sense of coherence--a concept influencing health and quality of life in a Swedish psychiatric at-risk group. Israel Journal of Medical Sciences, 32(3-4), 194-199.

Cooper, M. L., Frone, M. R., Russell, M., \& Mudar, P. (1995). Drinking to regulate positive and negative motions: A motivational model of alcohol use. Journal of personality and Social Psychology, 69, 9901005.

Contreras, L., Molina, V., \& Cano, M. C. (2012). Consumo de drogas en adolescentes con conductas infractoras: análisis de variables psicosociales implicadas. Adicciones, 24, 31-38.

Delegación del Gobierno para el Plan Nacional sobre Drogas (2009). Informe de la Encuesta Estatal sobre Uso de Drogas en Estudiantes de Enseñanzas Secundarias (ESTUDES) 2008. Madrid, Spain: Ministerio de Sanidad y Política Social.

De Vries, H., Engels, R. C. M. E., Kremers, S., Wetzels, J., \& Mudde, A. (2003). Parents' and friends' smoking status as predictors of smoking onset: Findings from six European countries. Health Education Research, 18, 627-636. doi: 10.1093/her/cyg032

Duncan, S. C., Duncan, T. E., \& Hops, H. (1998). Progressions of Alcohol, Cigarette, and Marijuana Use in Adolescence. Journal of Behavioral Medicine, 21, 375-388. doi: 10.1023/A:1018730814379

Eriksson, M., \& Lindström, B. (2006). Antonovsky's sense of coherence scale and the relation with health: A systematic review. Journal of Epidemiology and Community Health, 60, 376-381. doi: 10.1136/ jech.2005.041616

Essau, C. A. (2004). Risk-taking behaviour among German adolescents. Journal of Youth Studies, 7, 499-512. doi: 10.1080/1367626042000315248

Glanz, K., Maskarinec, G., \& Carlin, L. (2005). Ethnicity, sense of coherence, and tobacco use among adolescents. Annals of Behavioral Medicine, 29, 192-199. doi: 10.1207/ s15324796abm2903_5

Guo, J., Hill, K. G., Hawkins, J. D., Catalano, R. F., \& Abbott, R. D. (2002). A developmental analysis of sociodemographic, family, and peer effects on adolescent illicit drug initiation. Journal of American Academy Child and Adolescent Psychiatry, 41, 838-845. doi: 10.1097/00004583-200207000-00017

Hair, J. F., Anderson, R. E., Tatham, R. L., \& Black, W. C. (2008). Análisis multivariante (5th ed.). Madrid, Spain: Prentice Hall.

Hibell, B., Andersson, B., Ahlström, S., Balakireva, O., Bjarnasson, T., Kokkevi, A., \& Morgan, M. (2000). The 1999 European School Survey Project on Alcohol and Other Drugs (ESPAD) Report. Alcohol and other drug use among students in 30 European countries. Stockholm, Sweden: The Swedish Council for Information on Alcohol and Other Drugs (CAN) and The Pompidou Group at the Council of Europe.

Jaccard, J., Blanton, H., \& Dodge, T. (2005). Peer influences on risk behavior: An analysis of the effects of a close friend. Developmental Psychology, 41, 135-147. doi: 10.1037/0012-1649.41.1.135

Koposov, R. A., Ruchkin, V. V., \& Eisemann, M. (2003). Sense of coherence: A mediator between violence exposure and psychopathology in 
Russian juvenile delinquents. Journal of Nervous \& Mental Disease, 191, 638-644. doi: 10.1097/01.nmd.0000092196.48697.9d

Koushede, V. \& Holstein, B. E. (2009). Sense of coherence and medicine use for headache among adolescents. Journal of Adolescent Health, 45, 149-155. http://dx.doi.org/10.1016/j.jadohealth.2008.12.009

Kuntsche, E., \& Stewart, S. H. (2009). Why my classmates drink drinking motives of classroom peers as predictors of individual drinking motives and alcohol use in adolescence: A mediational model. Journal of Health Psychology, 14, 536-546. doi: 10.1177/1359105309103573

Lindström, B., \& Eriksson, M. (2010). The hitchhiker's guide to salutogenesis. Salutogenic pathways to health promotion. Helsinki, Finland: Folkhälsan Research Center.

March Cerdá, J. C., Prieto Rodríguez, M. A., Danet, A., Ruiz Azarola, A., García Toyos, N., \& Ruiz Román, P. (2010). Posicionamiento de padres y madres ante el consumo de alcohol en población de 12 a 17 años en el ámbito urbano de seis Comunidades Autónomas. Gaceta Sanitaria, 24, 53-58. doi: 10.1016/j.gaceta.2009.09.016

Myrin, B., \& Lagerström M. (2006). Health behaviour and sense of coherence among pupils aged 14-15. Scandinavian Journal of Caring Sciences, 20, 339-346. doi: 10.1111/j.1471-6712.2006.00413.x

Moral Jiménez, M. V., Rodríguez Díaz, F. J., \& Sirvent Ruiz, C. (2005). Motivadores de consumo de alcohol en adolescentes: análisis de las diferencias intergénero y propuesta de un continuum etiológico. Adicciones, 17, 105-120. Retrieved from: http://www.adicciones.es

Moreno, C., Ramos, P., Rivera, F., Muñoz-Tinoco, V., Sánchez-Queija, I., Granado, M. C., \& Jiménez-Iglesias, A. (2011). Desarrollo adolescente y salud en España. Resumen del estudio Health Behaviour in Schoolaged Children (HBSC - 2006). Madrid, Spain: Ministerio de Sanidad, Política Social e lgualdad.

Morgan, A., Jiménez-Iglesias, A., Owen, L., Rivera, F., Moreno, C., \& Haglund, B. (2012). Can we still be friends if I don't smoke: an asset based analysis of adolescent smoking behaviour in England and Spain? Manuscript submitted for publication.

Nilsson, K. W., Starrin, B., Simonsson, B., \& Leppert, J. (2007). Alcoholrelated problems among adolescents and the role of a sense of coherence. International Journal of Social Welfare, 16, 159-167. doi: $10.1111 / j .1468-2397.2006 .00452 . x$

Pettit, G. S., Bates, J. E., Dodge, K. A., \& Meece, D. W. (1999). The impact of after-school peer contact on early adolescent externalizing problems is moderated by parental monitoring, perceived neighborhood safety, and prior adjustment. Child Development, 70, 768-778. doi: 10.1111/1467-8624.00055

Rubin, K. H., Bukowski, W. M., \& Parker, J. G. (2006). Peer interactions, relationships, and groups. In N. Eisenberg (Ed.), Handbook of child psychology: Vol. 3. Social, emotional and personality development (6th ed., pp. 619-700). New Jersey, USA: John Wiley \& Sons.

Sagy, S., Shani, E., \& Leibovich, E. (2009). Factors related to attitudes towards drug use and alcohol drinking: Comparing immigrants from the former Soviet Union and Israeli-born adolescents. Journal of Substance Use, 14, 10-18. doi: 10.1080/14659890802305879

Salamó Avellaneda, A., Gras Pérez, M. E., \& Font-Mayolas, S. (2010). Patrones de consumo de alcohol en la adolescencia. Psicothema, 22, 189-195. Retrieved from http://www.psicothema.com/
Schofffild, P. E., Pattison, P. E., Hill, D. J., \& Borland, R. (2001). The influence of group identification on the adoption of peer group smoking norms. Psychology \& Health, 16, 1-16. doi: 10.1080/08870440108405486

Simões, C., Gaspar-Matos, M., Moreno, C., Rivera, F., Batista-Foguet, J. M., \& Simons-Morton, B. (in press). Substance use in Portuguese and Spanish adolescents: Highlights from differences and similarities and moderate effects. The Spanish Journal of Psychology.

Simons-Morton, B. G., Farhat, T., ter Bogt, T. F. M., Hublet, A., Kuntsche, E., Nic Gabhainn, S.,... the HBSC Risk Behaviour Focus Group (2009). Gender specific trends in alcohol use: Cross-cultural comparisons from 1998 to 2006 in 24 countries and regions. International Journal of Public Health, 54(Suppl. 2), 199-208. doi: 10.1007/s00038-009$5411-\mathrm{y}$

Sollerhed, A., Ejlertsson, G., \& Apitzsch, E. (2005). Predictors of strong sense of coherence and positive attitudes to physical education in adolescents. Scandinavian Journal of Public Health, 33, 334-342. doi: 10.1080/14034940510005833

Suominen, S., Blomberc, H., Helenius, H., \& Koskenvuo, M. (1999). Sense of coherence and health - Does the association depend on resistance resources? A study of 3115 adults in Finland. Psychology \& Health, 14, 937-948. doi: 10.1080/08870449908407358

Trucco, E. M., Colder, C. R., Bowker, J. C., \& Wieczorek, W. F. (2011). Interpersonal goals and susceptibility to peer influence: Risk factors for intentions to initiate substance use during early adolescence. The Journal of Early Adolescence, 31, 526-547. doi: $10.1177 / 0272431610366252$

Trujillo, A. M., Pérez, A., \& Scoppetta, 0. (2011). Influencia de variables del entorno social sobre la ocurrencia de situaciones problemáticas asociadas al consumo de alcohol en adolescentes. Adicciones, 23, 349-356.

Véronneau, M.-H., \& Dishion, T. J. (2010). Predicting change in early adolescent problem behavior in the middle school years: A mesosystemic perspective on parenting and peer experiences. Journal of Abnormal Child Psychology, 38, 1125-1137. doi: 10.1007/ s10802-010-9431-0

Wainwright, N. W. L., Surtees, P. G., Welch, A. A., Luben, R. N., Khaw, K-T., \& Bingham, S. A. (2007). Healthy lifestyle choices: Could sense of coherence aid health promotion? Journal of Epidemiology \& Community Health, 61, 871-876. doi: 10.1136/jech.2006.056275

Windle, M. (1999). Alcohol use among adolescents. Thousands Oaks, USA: Sage.

Windle, M. (2000). Parental, sibling, and peer influences on adolescent substance use and alcohol problems. Applied Developmental Science, 4, 98-110. doi: 10.1207/S1532480XADS0402_5

Zimmermann, G. (2010). Risk perception, emotion regulation and impulsivity as predictors of risk behaviours among adolescents in Switzerland. Journal of Youth Studies, 13, 83-99. doi: 10.1080/13676260903173488

Zuckerman, M., \& Kuhlman, D. M. (2000). Personality and risk-taking: Common biosocial factors. Journal of Personality, 68, 999-1029. doi: $10.1111 / 1467-6494.00124$ 


\section{Appendix 1. Cluster analysis of the patterns of}

substance use in the adolescents' peer group

\section{Aims}

The aim of this analysis was to classify adolescents according to the patterns of substance use that characterized their peer groups.

\section{Procedure}

Firstly, a two-step cluster analysis was carried out, which included the four variables related to peers' patterns of substance use described in the measures section. The two-step procedure was selected because it does not require to specify a fixed number of clusters prior analysis. Furthermore, it is an appropriate procedure for large samples.

Secondly, k-means cluster analysis was employed in the same sample and the level of agreement between the two procedures was examined in order to ensure the validity of the obtained clusters. Kappa index was the statistic employed in this validation procedure. Specifically, the following criteria were followed in the interpretation of the kappa index (Landis \& Koch, 1977): insignificant agreement (from 0 to 0.19), low agreement (from .20 to .39), medium agreement (from .40 to .59), high agreement (from .60 to .79) and very high agreement (.80 to 1$)$.

\section{Results}

Three different patterns of substance use in the adolescents' peer group were found by two-step cluster analysis. In addition, comparable groups were achieved with k-mean cluster analysis (kappa index of .79), which implies a high level of agreement between the two procedures and is an indicator of the validity of the obtained results.

Tables 1 and 2 summarize the main information about the three obtained groups in the cluster analysis.

According to the most outstanding characteristics of the three groups (see Table 2) they were labeled as follow: Pattern of no consumption (group 1), pattern of frequent alcohol use and occasional drunkenness (group 2), pattern of frequent substance use including illegal drugs (group 3).

Table 1. Classification of adolescents' peer group according to their patterns of substance use

\begin{tabular}{llll}
\hline & Frequency & Percentage & Valid percentage \\
\hline Group 1 & 1575 & $28.8 \%$ & $35.6 \%$ \\
\hline Group 2 & 1706 & $31.1 \%$ & $38.5 \%$ \\
\hline Group 3 & 1148 & $21.0 \%$ & $25.9 \%$ \\
\hline Valid Total & 4429 & $80.9 \%$ & $100 \%$ \\
\hline Missing & 1046 & $19.1 \%$ & \\
\hline Total & 5475 & $100 \%$ & \\
\hline
\end{tabular}

Table 2. Distribution of the three groups obtained in the cluster analysis on the different variables employed in the analysis

\begin{tabular}{|c|c|c|c|c|c|c|c|c|}
\hline & \multicolumn{2}{|l|}{ Total } & \multicolumn{2}{|c|}{ Group 1} & \multicolumn{2}{|c|}{ Group 2} & \multicolumn{2}{|c|}{ Group 3} \\
\hline & $\mathrm{N}$ & $\%$ & $\mathrm{~N}$ & $\%$ & $\mathrm{~N}$ & $\%$ & $\mathrm{~N}$ & $\%$ \\
\hline \multicolumn{9}{|l|}{$\begin{array}{l}\text { Peers' tobacco } \\
\text { use }\end{array}$} \\
\hline $\begin{array}{l}\text { Never or almost } \\
\text { never }\end{array}$ & 2041 & $45.4 \%$ & 1319 & $83.7 \%$ & 584 & $34.2 \%$ & 99 & $8.6 \%$ \\
\hline Sometimes & 1243 & $27.6 \%$ & 222 & $14.1 \%$ & 618 & $36.2 \%$ & 379 & $33.0 \%$ \\
\hline Very often & 1216 & $27.0 \%$ & 34 & $2.2 \%$ & 504 & $29.5 \%$ & 670 & $58.4 \%$ \\
\hline \multicolumn{9}{|l|}{ Peers' alcohol use } \\
\hline $\begin{array}{l}\text { Never or almost } \\
\text { never }\end{array}$ & 1012 & $22.5 \%$ & 953 & $60.5 \%$ & 7 & $.4 \%$ & 28 & $2.4 \%$ \\
\hline Sometimes & 1934 & $43.0 \%$ & 622 & $39.5 \%$ & 875 & $51.3 \%$ & 413 & $36.0 \%$ \\
\hline Very often & 1554 & $34.5 \%$ & 0 & $.0 \%$ & 824 & $48.3 \%$ & 707 & $61.6 \%$ \\
\hline \multicolumn{9}{|l|}{$\begin{array}{l}\text { Peers' drunken- } \\
\text { ness }\end{array}$} \\
\hline $\begin{array}{l}\text { Never or almost } \\
\text { never }\end{array}$ & 1836 & $40.7 \%$ & 1553 & $98.6 \%$ & 156 & $9.1 \%$ & 92 & $8.0 \%$ \\
\hline Sometimes & 1767 & $39.2 \%$ & 22 & $1.4 \%$ & 1183 & $69.3 \%$ & 533 & $46.4 \%$ \\
\hline Very often & 904 & $20.1 \%$ & 0 & $.0 \%$ & 367 & $21.5 \%$ & 523 & $45.6 \%$ \\
\hline \multicolumn{9}{|l|}{ Peers' drug use } \\
\hline $\begin{array}{l}\text { Never or almost } \\
\text { never }\end{array}$ & 3296 & $73.5 \%$ & 1553 & $98.6 \%$ & 1706 & $100.0 \%$ & 0 & $.0 \%$ \\
\hline Sometimes & 780 & $17.4 \%$ & 22 & $1.4 \%$ & 0 & $.0 \%$ & 740 & $64.5 \%$ \\
\hline Very often & 411 & $9.2 \%$ & 0 & $.0 \%$ & 0 & $.0 \%$ & 408 & $35.5 \%$ \\
\hline
\end{tabular}

\section{References}

Landis, J. R., \& Koch, G. G. (1977). The measurement of observer agreement for categorical data. Biometrics, 33, 159-174. 